\title{
Proteção ao conhecimento: análise dos impactos positivos e negativos do vazamento de conhecimento em empresas no Brasil e no Reino Unido
}

\section{Maria Celeste Reis Lobo Vasconcelos}

\author{
Professora do Corpo Permanente do \\ Mestrado Profissional em Administração \\ da Fundação Pedro Leopoldo
}

George Leal Jamil

\begin{abstract}
Doutor em Ciência da Informação pela ECI/UFMG. Professor do Mestrado em Administração da Universidade Fumec-
\end{abstract}

O vazamento ou fuga de conhecimento (knowledge leakage ou knowledge seepage) se refere tanto à absorção como à transferência de conhecimento, que acontece na interação das empresas com o ambiente de trabalho. $O$ artigo tem o objetivo de analisar as rotas de vazamento de conhecimento em empresas no Brasil e no Reino Unido, usando taxonomia apresentada na literatura. Nos estudos de caso realizados, concluiu-se que as empresas brasileiras ainda precisam se preparar melhor para a proteção do seu conhecimento estratégico.

Palavras-chave: Gestão do conhecimento; Proteção ao conhecimento; Vazamento de conhecimento; Impacto positivo e negativo.

\section{Knowledge protection: an analysis of positive and negative impacts due to knowledge leakage in Brazilian and United Kingdom enterprises.}

Knowledge leakage or knowledge seepage refers to both knowledge absorption and transfer that happens in the interaction of companies with their working environment. This work aims to analyze the knowledge leakage routes in Brazilian and United Kingdom companies, using the 
taxonomy presented in the literature. The case studies lead to the conclusion that Brazilian companies need to prepare themselves better for the protection of their strategic knowledge.

Keywords: Knowledge management, knowledge protection, knowledge leakage, positive and negative impacts.

Recebido em 25.02.2008 Aceito em 13.10.2008

\section{Introdução}

Observa-se, hoje, que a maior parte do valor dos produtos das empresas é produzida em redes e não mais isoladamente por uma única empresa (CASTELLS, 2000). Estas redes têm a principal função estratégica de propiciar competitividade com dinamismo e versatilidade, formando arranjos de alto valor agregado que disputam mercados em praças variadas (REAGANS e Mc EVILY, 2003). Portanto, recursos que são críticos para a competitividade das empresas, tal como o conhecimento e a inovação, precisam ser compartilhados, explorados e aplicados, dentro da perspectiva das redes. (DYER \& NOBEOKA, 2000; GULATI, NOHRIA \& ZAHEER, 2000, TEIXEIRA ET AL, 2005, VASCONCELOS ET AL, 2005).

Esta estrutura em rede criou uma grande complexidade nos ambientes internos e externos das organizações, e aumentou os esforços para uma efetiva gestão do conhecimento estratégico e da inovação. Este tema representa hoje um assunto central para inúmeras pesquisas que procuram captar a sofisticação das relações entre as empresas e caracterizar a dinâmica competitiva das cadeias produtivas na atualidade. Um dos pontos mais importantes a serem observados e compreendidos, neste contexto, é o aumento expressivo do fluxo de conhecimento intra e inter empresas, e a análise dos seus impactos, que podem ser positivos ou negativos. Na chamada sociedade do conhecimento, o crescente fluxo de novos conhecimentos que mantém os mercados em movimento contínuo tem requerido das empresas uma concentração na sua capacidade inovativa. Dyer (1996) argumenta que empresas que participam de redes podem levar vantagem em relação às empresas independentes, porque seus parceiros podem fornecer-lhes recursos e informações que respondam efetivamente a choques exógenos. Assim, ele enfatiza que o valor adicionado da empresa vem da conversão dos seus ativos genéricos (capital, matéria prima, competências gerais, etc.) para ativos especializados (tecnologia, competências centrais, processos especializados, etc.), e que estes ativos especializados podem ser produtos da relação da empresa com os seus parceiros de negócios. O relacionamento cooperativo, além de dar acesso ao conhecimento dominado pelo parceiro, permite que a empresa ainda mantenha e 
melhore suas habilidades centrais. (BESSANT, KAPLINSKY, ET AL., 2003, 2003 a).

Para Kale, Singh \& Perlmutter (2000), os estudos sobre redes estão tendendo para a questão do aprendizado. A possibilidade de acessar ou adquirir informações críticas, know-how ou capacitações do parceiro são freqüentemente citadas como sendo as maiores motivações para a formação de redes. Estas redes são vistas, não somente como um meio de negociar acesso às capacitações complementares do outro, mas também como um mecanismo para adquirir ou internalizar as técnicas e habilidades do parceiro. Os autores ressaltam que alianças com o objetivo de aprendizagem constituem uma importante classe de aliança. As empresas enfrentam o desafio de gerenciar o equilíbrio entre aprender e proteger os seus conhecimentos estratégicos (TEIXEIRA ET AL, 2005). Yoshino e Rangan (1996) também ressaltam que o aprendizado é sempre um objetivo estratégico implícito para cada empresa que participa de redes. Tais redes englobam o conjunto, tanto horizontal como vertical, de relacionamentos de uma empresa com outras organizações - sejam elas fornecedores, clientes, competidores, ou outras entidades - incluindo relações entre indústrias e países. Estas redes estão compostas muitas vezes de laços duradouros, de significado estratégico para as empresas que entram nelas, e incluem alianças estratégicas, empreendimentos conjuntos e parcerias de longo prazo. Segundo Gulati, Nohria, \& Zaheer (2000), as redes fornecem às empresas informações, conhecimentos, recursos, acesso a outros mercados e a outras tecnologias; favorecem o aprendizado e podem gerar economias de escala e de escopo, dentre outros. Dyer \& Nobeoka (2000) argumentam que estas redes podem ser meios eficazes de aprendizagem inter organizacional, onde os clientes e os fornecedores podem vir a ser fontes primárias de inovação. (VASCONCELOS ET AL, 2005).

Algumas questões especiais emergem quando se observa 0 posicionamento e o valor dos profissionais, empregados diretos, terceirizados, alocados temporariamente ou mesmo contratados de prestadores de serviços, para a formação destas redes. A literatura ressalta várias iniciativas de empresários e demais formadores das redes empresariais no sentido de definir políticas de gestão de recursos humanos destinadas a manter, proteger e valorizar o capital intelectual desenvolvido, adquirido e formado através da evolução do trabalho dos profissionais que atuam nestes complexos sistemas organizacionais. (CHOO, 1998; JAMIL, 2006)

Deve ainda ser ressaltado que tais redes se formam com apoio intensivo de tecnologia da informação e de comunicação, para atuar como preconizado, em termos de competitividade e flexibilidade, formando cadeias produtivas inovadoras (LUCAS, 2006). Entretanto, tais redes tecnológicas trazem, como contrapartida ao atendimento aos pressupostos estratégicos de maior dinamismo e versatilidade, vulnerabilidades advindas da complexidade e interconexões de equipamentos, software, e da interação entre usuários, que se comunicam 
através da interface provida pelo aparato de poderosos sistemas de informação.

Outro aspecto ressaltado por vários autores é o fato de que as empresas não conseguem ao mesmo tempo ser competitivas e desempenhar todas as atividades dentro da sua cadeia de valor. Elas precisam se concentrar nas suas competências essenciais (PRAHALAD \& HAMEL, 2000) e terceirizar outras atividades. A terceirização tem sido praticada de forma crescente, principalmente para fornecedores nos países em desenvolvimento, como por exemplo, a China. A governança da rede passa a ser uma competência essencial para as empresas mais competitivas. Achar uma posição sustentável dentro desta crescente cadeia de valor global passa a ser um desafio constante para as empresas, pois elas passam então a ter de enfrentar o duplo desafio de aproveitar e usar os novos conhecimentos oferecidos pelos parceiros e, ao mesmo tempo, assegurar que conhecimentos estratégicos, que constituem competências essenciais, não sejam vazados nestas redes. É neste contexto que se ressalta a importância dos conceitos de proteção e de vazamento de conhecimento. (KAPLINSKY ET AL, 2006).

O objetivo do artigo é entender como as empresas estão lidando com o vazamento de conhecimento e suas conseqüências, visando proteger o seu conhecimento estratégico. No artigo se analisou as diferentes rotas de vazamento e como as empresas entendem este conceito. Inicialmente são discutidos os impactos positivos ou negativos que o vazamento de conhecimento, intencional ou não, pode ocasionar na competitividade das empresas. São apresentados os resultados de uma pesquisa exploratória sobre o tema, envolvendo entrevistas com gestores de empresas de grande porte no Brasil, e uma comparação com estudos de caso realizados na Inglaterra.

\section{O vazamento de conhecimento}

O conceito de vazamento de conhecimento (knowledge leakage) ainda representa um ponto pouco discutido na literatura sobre gestão do conhecimento. Outros termos podem ser encontrados para designar este fenômeno: perda ou fuga de conhecimento (knowledge loss), escoamento de conhecimento (knowledge seepage) ou exposição/revelação de conhecimento (knowledge disclosure). Annansingh (2005) define 0 vazamento de conhecimento como sendo a possibilidade de informações e conhecimentos, críticos para a organização, serem perdidos ou vazados, de forma deliberada ou não, para um competidor ou pessoa não autorizada.

É importante ressaltar que o vazamento de conhecimento se refere tanto à absorção como à transferência de conhecimento, que acontece na interação das empresas com 0 seu ambiente de trabalho. As conseqüências ou impactos desse vazamento, na vida das empresas, podem ser positivos ou negativos. Por exemplo, compartilhar conhecimento na cadeia de suprimento pode ocasionar a melhoria de 
produtos e de processos e, consequentemente, aumentar a competitividade da organização. Por outro lado, compartilhar conhecimento estratégico de forma inadequada (ou para um parceiro inadequado) pode ocasionar a diminuição da competitividade. Entender esta dinâmica do processo de vazamento de conhecimento e de suas conseqüências traz novos desafios para as empresas na utilização total ou parcial dos seus conhecimentos estratégicos nas suas parcerias. Devido à sua importância, o vazamento de conhecimento precisa ser analisado e entendido, principalmente no contexto das redes, em que as empresas estão inseridas (MOHAMED ET AL, 2006).

Várias são as situações que permitem vislumbrar a avaliação positiva ou negativa do vazamento de conhecimento, quando se verificam processos decisórios típicos da gestão, considerados ainda sob a ótica da atuação em rede. Entre estes casos, verificam-se em Kotler e Armstrong (2003), com relação ao processo de marketing, e em Kalakota e Robinson (2002), em relação a aspectos da cadeia de suprimentos integrada através de sistemas tecnológicos de Business to Business (identificados pela sigla B2B) e de suporte à gestão de logística propriamente dita, nas soluções denominadas Supply Chain Management (identificados pela sigla SCM). Tais situações, entre várias outras, permitem tanto verificar a complexidade das redes quanto avaliar as interações nos inúmeros processos decisórios destinados ao planejamento e à execução destas atividades, apontando os riscos (negativos) e possíveis benefícios (positivos) do vazamento de conhecimento.

Segundo Kaplinsky et al (2006), o vazamento de conhecimento precisa ser analisado de forma integrada na empresa, e deve ser observado o balanço entre perdas e ganhos de conhecimento que acontecem nas ligações entre as empresas. Os autores destacam que a análise do vazamento de conhecimento nas organizações envolve vários campos de estudo, como: gestão do conhecimento e da inovação, estratégia, recursos humanos, análise de risco, cadeias de suprimento, cadeias de valor, competências essenciais, análise de produtividade, confiança, pesquisa e desenvolvimento, etc. Segundo os autores, a literatura falha ao não dar ênfase ao vazamento positivo de conhecimento. Outros pontos pouco discutidos na literatura são: o grau de intencionalidade do vazamento de conhecimento, a avaliação estratégica do fato "vazamento de conhecimento" e as estratégias de proteção aos conhecimentos usados pelas organizações.

\section{Vetores do vazamento de conhecimento}

Kaplinsky et al (2006) observam que o vazamento de conhecimento envolve seis diferentes vetores, que são: fornecedores, clientes, competidores, os recursos humanos da empresa, o relacionamento da empresa com o sistema de inovação e as ações relacionadas à propriedade intelectual. Em cada um destes vetores, a empresa terá múltiplas formas de interação com outras organizações. Estas interações 
podem envolver ações intencionais (por exemplo, a entrega de manuais para clientes ou para fornecedores) ou não intencionais (como perda de equipe de projetos através da terceirização da atividade). Os impactos destes vazamentos podem ser positivos ou negativos.

Mohamed et al (2006) propõem um modelo para análise do vazamento de conhecimento através do fluxo de pessoas na organização. O modelo (FIG 1) caracteriza o vazamento em dois grupos: intencional e não intencional. Além disto, o modelo caracteriza o tipo de impacto ocorrido: positivo ou negativo. O modelo proposto permite uma análise da estrutura do vazamento de conhecimento, que pode ser utilizado pelas empresas no desenvolvimento de estratégias para a proteção dos conhecimentos que compõem suas competências essenciais.

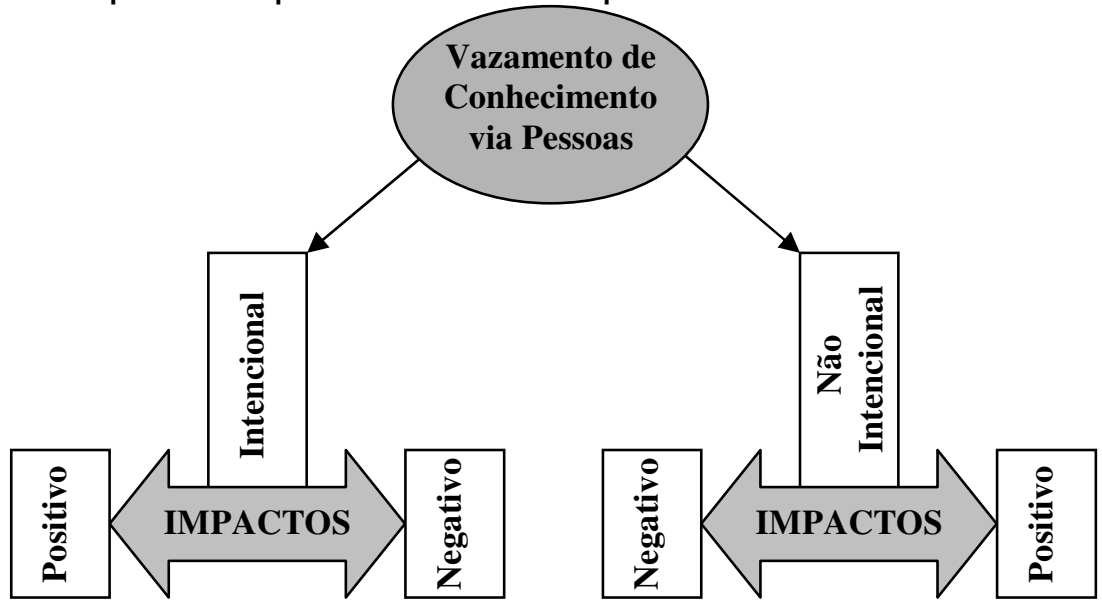

FIGURA 1: Taxonomia do Vazamento de Conhecimento através das Pessoas

Fonte: Mohamed et al (2006)

Mohamed et al (2006) ressaltam que:

- O vazamento de conhecimento é hoje um conceito crescentemente estratégico. O desafio para as empresas é fazer uma análise do fluxo de conhecimento de forma explícita e intencional, que normalmente é feita de forma implícita e não intencional.

- É preciso criar rotinas que potencializem os impactos positivos de vazamento de conhecimento e reduzam os impactos negativos. Isto deve ser feito em todos os níveis da empresa.

- As empresas precisam reconhecer que trabalham em diferentes redes, com diferentes graus de confiança entre os membros.

- O vazamento de conhecimento acontece tanto nas grandes como nas pequenas e médias empresas.

Os autores desenvolveram uma pesquisa para identificar as rotas de vazamento de conhecimento que acontece através das pessoas nas empresas. As principais rotas identificadas se encontram no Quadro 1.

Deve ser contemplado, em adição, segundo levantado na revisão de literatura feita anteriormente, que o vazamento de conhecimento, ao 
envolver processos decisórios estratégicos, implica em valorizar pesquisas sobre o tema, uma vez que a atuação empresarial em rede torna-se, no atual panorama, irreversível, assim como sua complexidade e uso de infra-estruturas tecnológicas.

Com base na importância do impacto do vazamento de conhecimento nas empresas, foi elaborada uma pesquisa exploratória com empresas brasileiras para identificar as principais rotas de vazamento. Para a análise dos dados, foi utilizada a taxonomia de vazamento de conhecimento proposto por Mohamed et al (2006), isto é, que o vazamento pode ser intencional ou não, com impactos positivos ou negativos.

\section{QUADRO 1: Vazamento de Conhecimento através das Pessoas e seus} Impactos

\begin{tabular}{|c|c|c|c|}
\hline \multirow{2}{*}{$\begin{array}{c}\text { Forma de } \\
\text { Vazamento } \\
\text { de Conheci- } \\
\text { mento. }\end{array}$} & \multirow{2}{*}{$\begin{array}{l}\text { Fontes de Vazamento de } \\
\text { Conhecimento via pessoas } \\
\text { (E-Entrada e S-Saídas) }\end{array}$} & \multicolumn{2}{|c|}{ Impacto do Vazamento de Conhecimento } \\
\hline & & Positivo & Negativo \\
\hline \multirow{7}{*}{ 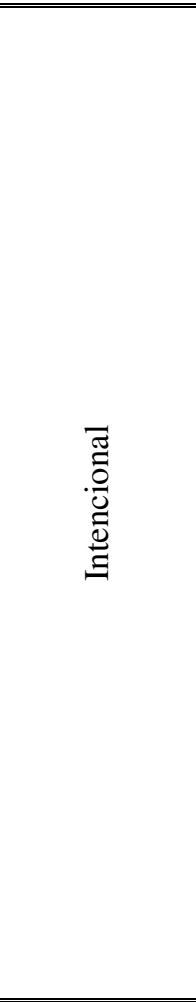 } & Cursos de treinamento $(\mathrm{E})$ & $\begin{array}{c}\text { Participar de cursos } \\
\text { externos traz idéias }(\mathrm{E}) \text { e } \\
\text { cria futuras capacidades }\end{array}$ & - \\
\hline & $\begin{array}{l}\text { Envolvimento de pessoas } \\
\text { nas estratégias do negócio } \\
\text { (S) }\end{array}$ & $\begin{array}{l}\text { As pessoas sentem que } \\
\text { têm uma parcela do } \\
\text { negócio e que possuem a } \\
\text { direção da organização } \\
(\mathrm{E}, \mathrm{S})\end{array}$ & - \\
\hline & $\begin{array}{c}\text { Colaboração com } \\
\text { universidades incluindo } \\
\text { parcerias de transferência de } \\
\text { conhecimento }(\mathrm{E}, \mathrm{S})\end{array}$ & $\begin{array}{l}\text { Ganho de novos insights e } \\
\text { informações de fontes } \\
\text { externas (E) }\end{array}$ & $\begin{array}{c}\text { Divulgação das práticas e } \\
\text { informações da companhia para } \\
\text { organizações externas }(\mathrm{S})\end{array}$ \\
\hline & $\begin{array}{l}\text { Pessoas que vêm de outras } \\
\text { organizações (E,S) }\end{array}$ & $\begin{array}{c}\text { Aproveitar o } \\
\text { conhecimento de outras } \\
\text { pessoas }(\mathrm{E})\end{array}$ & $\begin{array}{l}\text { Transmissão de informações ou } \\
\text { conhecimentos importantes } \\
\text { para organizações externas (S) }\end{array}$ \\
\hline & $\begin{array}{l}\text { Equipes multidisciplinares } \\
\text { (E,S) }\end{array}$ & $\begin{array}{l}\text { Aprendizado entre } \\
\text { disciplinas (E,S) }\end{array}$ & $\begin{array}{l}\text { Equipes podem estar além das } \\
\text { fronteiras da empresa ou entre } \\
\text { subsidiárias }(\mathrm{S})\end{array}$ \\
\hline & $\begin{array}{l}\text { Trabalhadores temporários } \\
\text { ou terceirizados (E,S) }\end{array}$ & $\begin{array}{l}\text { Conhecimento se } \\
\text { beneficia da entrada de } \\
\text { novas pessoas }\end{array}$ & $\begin{array}{c}\text { Trabalhadores temporários } \\
\text { podem sair com conhecimento } \\
\text { da firma e de seus processos e } \\
\text { estratégias }(\mathrm{S})\end{array}$ \\
\hline & $\begin{array}{c}\text { Perda temporária ou } \\
\text { antecipada de pessoal (S) }\end{array}$ & - & $\begin{array}{c}\text { Ruptura dos processos de } \\
\text { trabalho (ex.: férias e licenças) }\end{array}$ \\
\hline \multirow{2}{*}{ 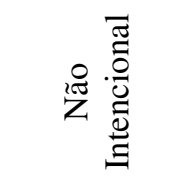 } & $\begin{array}{l}\text { Perda temporária ou } \\
\text { antecipada de pessoal }(\mathrm{S})\end{array}$ & - & $\begin{array}{c}\text { Ruptura dos processos de } \\
\text { trabalho (ex.: doença e licença } \\
\text { maternidade) }(\mathrm{S})\end{array}$ \\
\hline & Pessoal saindo $(\mathrm{S})$ & - & Perda de experts $(\mathrm{S})$ \\
\hline
\end{tabular}

Fonte: Mohamed et al (2006)

O próximo item apresenta a metodologia utilizada na pesquisa. 


\section{Aspectos metodológicos}

A pesquisa que subsidiou os resultados deste estudo pode ser caracterizada como um estudo de campo exploratório, de caráter qualitativo, realizado por meio da técnica de entrevistas, utilizando questionário aberto. Foi realizada uma investigação empírica junto a 4 (quatro) gerentes de 4 (quatro) empresas de grande porte nacionais e multinacionais, atuantes no Brasil, para obter dados sobre vazamento de conhecimento e seus impactos, nos setores listados abaixo:

- Empresa 1: do setor eletroeletrônico

- Empresa 2: do setor de mineração

- Empresa 3: do setor automobilístico

- Empresa 4: do setor de equipamentos eletrônicos (distribuição)

A pesquisa pode, ainda, ser classificada como de natureza descritiva, uma vez que se propõe à obtenção e exposição de dados representativos de determinada situação ou fenômeno. Segundo Rudio (1986, p. 56), o propósito desse tipo de pesquisa é "descobrir e observar fenômenos, procurando descrevê-los, classificá-los e interpretá-los". Este trabalho é ainda um estudo de caso, uma vez que está circunscrito a poucas empresas e tem o objetivo de examinar acontecimentos contemporâneos (YIN, 2001). Os levantamentos feitos foram estudados posteriormente à sua coleta, visando categorização do conteúdo, para melhor elaboração das conclusões do estudo, como recomenda Gil (2002).

$O$ roteiro de entrevista usado na pesquisa foi o mesmo utilizado por Mohamed et al (2006) e foi enviado inicialmente via internet, para que os entrevistados tomassem conhecimento sobre as questões a serem respondidas. Depois disto, vários contatos foram feitos com os entrevistados, tanto por e-mail como por telefone, no sentido de eliminar dúvidas, tanto relativas às perguntas como às respostas. As respostas obtidas nas entrevistas foram agrupadas e analisadas na tentativa de uma categorização.

Considera-se que a pesquisa seja relevante, pois ainda não são bem compreendidas as rotas através das quais o conhecimento vaza das empresas. Só após esta compreensão será possível proteger o conhecimento estratégico das empresas, maximizando os impactos positivos e minimizando os impactos negativos deste vazamento. A pesquisa pode propiciar um maior conhecimento sobre estes mecanismos, de forma a dar suporte às empresas na busca da competitividade. A conscientização dos riscos potenciais do fluxo sem controle, de conhecimentos específicos, pode subsidiar, no futuro, políticas governamentais, e oferecer às empresas um guia para uma adequada participação em redes, na busca pela inovação e competitividade. 


\section{Análise dos resultados}

As respostas dos gerentes empresariais, em relação a temas ligados à gestão e proteção do conhecimento e, especificamente, sobre o vazamento de conhecimento e suas rotas foram agrupadas numa tentativa de categorização.

\section{Gestão do conhecimento e mensuração do impacto do conhecimento}

Sabe-se que a definição e o controle de indicadores de gestão do conhecimento ainda representam um desafio para as organizações. Esta dificuldade ficou bem evidenciada nas respostas dos gerentes, quando questionados sobre a importância do conhecimento e as medidas usadas pela empresa para mensurar o sucesso do conhecimento. Com exceção do indicador de número de patentes, que é um indicador que mede resultados, os outros indicadores citados foram de esforço:

Os produtos estão cada vez mais complexos e o conhecimento embutido neles é múltiplo. Ninguém individualmente domina o conjunto completo. Por um lado, isso reduz o impacto, por outro lado, aumenta a importância de reduzir as perdas de conhecimento. O emprego de PDT Product Development Team e engenharia simultânea contribuem para o paralelismo das atividades e compartilhamento do conhecimento geral. Uma medida do sucesso do conhecimento usada na empresa é o número de patentes requisitadas, superior a 4 mil por ano na empresa. (E1)

O conhecimento foi um dos fatores críticos que mais contribuiu para que a companhia chegasse aonde chegou e com as perspectivas futuras que possui. Entretanto, mensurar o valor do conhecimento é um dos desafios que as organizações devem enfrentar na era do conhecimento. (...). É preciso que se perceba que essa nova dimensão dada ao conhecimento traz à tona questões delicadas, complexas e multifacetadas para as organizações, seus gerentes e seus respectivos tomadores de decisão. (E2)

Acredito que temos boas práticas já consolidadas tais como relacionamento com universidades na formação de nossos empregados e no desenvolvimento de novos conhecimentos; adoção de mapas de competências em todas as áreas da organização como instrumento de gestão e desenvolvimento de pessoas. Possuímos uma Universidade Corporativa para atender as necessidades de treinamento. Porém, não percebo um sistema integrado e planejado para a gestão do conhecimento (E3)

Avaliamos a importância do conhecimento embutido nos nosso produtos pelo feedback dos clientes que podem qualificar o quanto nosso suporte de informação e conhecimento os ajuda e nos habilita a fechar negócios e ser reconhecido como confiável. Também serve para nos balizar em relação ao mercado (E4) 
Foi perguntado aos entrevistados se as respectivas empresas tinham estratégias de captura de conhecimento. Algumas empresas ainda se mostraram na fase inicial da estruturação de sistemas de captura.

As ferramentas de TI como groupware e portais de uso coletivo facilitam o registro de conhecimento (E1)

A possível solução passa por uma Transferência Estruturada do Conhecimento através de um processo sistemático e devidamente orientado, em que o detentor e o receptor do conhecimento são levados a refletir sobre as suas realidades e os aspectos importantes para o bom desempenho da função. Associado a isto, também devem ser tomadas medidas de cunho jurídico com vistas a assegurar o sigilo com relação a informações estratégicas. (E2)

Não existe uma estratégia robusta e compartilhada pela alta direção neste sentido, o que ocorre são algumas práticas internas. Usamos multiplicadores internos, metodologia de gestão chamada trabalho padronizado, que permite a todos os turnos trabalharem de forma padronizada (neste processo o conhecimento tácito é explicitado). No ambiente de produção temos grupos de metodologistas e Condutores de Processos que têm o papel de atuarem como "Treinadores" do pessoal operacional. A empresa possui procedimentos $e$ normas que regulamentam todas as suas atividades, a maioria está disponível na intranet do Grupo. Estes procedimentos e normas não são apenas focados no sistema de funcionamento da empresa, mas também temos procedimentos e normas técnicas que orientam o desenvolvimento, a fabricação e a verificação de qualidade de nossos produtos e dos produtos fornecidos por terceiros. (E3).

Não, a empresa não tem mecanismos de captura de conhecimento estruturado. (E4)

\section{Conceito de vazamento de conhecimento}

Quando questionados sobre a definição do termo "vazamento de conhecimento" e as suas conseqüências, os entrevistados se mostraram informados sobre esta questão e preocupados com os impactos deste vazamento para a empresa. Alguns trechos citados abaixo mostram esta preocupação. Observa-se que o vazamento é ainda fortemente associado aos impactos negativos, e não aos impactos positivos, conforme descrito na literatura.

A perda do conhecimento é muito grave para nossa empresa, cuja base é a inovação. Nosso maior desafio tem sido lidar com perdas de funcionários para outras empresas (E1)

O termo fuga do conhecimento significa que informações consideradas sigilosas escapam para o ambiente através das interações da empresa ou de seus funcionários com outros elementos do mercado. (E2)

Para mim significa a perda de conhecimento importante ou estratégico para a organização, seja por perda de recursos humanos, 
vazamento de conhecimentos estratégicos, falhas de sistemas informativos, entre outros (E3)

Significa a transferência do conhecimento para dentro e fora da organização (E4).

\section{Rotas de vazamento}

As principais rotas de vazamento de conhecimento citadas, com impacto negativo, foram: roubo, desleixo ou indiferença do colaborador, falhas no sistema eletrônico, participação em conferências, consultores, revistas e jornais da empresa, espionagem industrial, profissionais terceirizados, atividade de co- design com fornecedores e as estruturas matriciais para a elaboração de projetos. Foram ressaltadas as preocupações relativas à rota de vazamento via consultores. Observa-se, mais uma vez, pelas respostas obtidas, que 0 vazamento do conhecimento está fortemente ligado aos impactos negativos. A seguir se encontram alguns trechos das declarações dos pesquisados sobre as várias rotas de vazamento de conhecimento.

Roubo:

Sim. Já ocorreu gerando perdas em concorrências. Estagiário demitido. (E1)

Indiferença do colaborador:

Pouco freqüente. Empresa remunera cross-selling (indicações de negócios feitas por um colaborador para outras áreas de negócios). (E1)

Sistemas de informação:

O vazamento é pouco freqüente. Uso crescente de mensagens e arquivos criptografados usando crachá com chip (smart-card) (E1)

Pouco prováveis. Os sistemas geralmente não falham. (E2)

Sim, já houve perdas de informação por problemas de backup. (E4)

Participação em conferências:

Nestes eventos não são fornecidos detalhes tecnológicos. A abordagem é comercial com mínimo de técnica. (E1)

Representa ótima oportunidade para a prática de Benchmarking e Engenharia Social. (E2)

\section{Consultores:}

Canal perigoso. Pode ocorrer. (E1)

Particularmente eu os considero muito perigosos. (E2)

Revistas e jornais da empresa:

Já ocorreu de vazar informações sobre grandes negócios e que podem ser usados pelos concorrentes. O inverso também existe. Descobri muita coisa lendo o jornal da concorrente. (E1)

\section{Gestão do vazamento de conhecimento}

Outra questão colocada aos gerentes foi relativa à gestão do vazamento de conhecimento. As respostas mostraram que algumas empresas estão desenvolvendo ações para minimizar o vazamento 
negativo, principalmente em relação à retenção de talentos, análise de risco e proteção física dos sistemas:

Trabalha-se com estratégias de proteção física e de retenção de talentos. (E1)

Através de procedimentos internos sigilosos. A título de informação, são executados procedimentos tais como: identificação dos perigos e análise do risco; identificação, análise e aprovação das medidas de controle; implementação das medidas de controle do risco e avaliação dos riscos residuais; monitoramento e revisão das medidas de controle do risco. (E2)

Temos a identificação de um grupo de pessoas classificados como Key People. Para estes fazemos uma gestão mais particularizada, ou seja, seguimos de perto no intuito de fazermos uma política de retenção, porém não declarada e bastante sutil. (E3)

Não temos um processo de gerenciamento de risco (E4)

Um dos blocos de perguntas da pesquisa focalizou as principais causas de saída das pessoas da empresa, seja por aposentadoria, nova oportunidade profissional, promoção, etc. O objetivo era explorar quão dependente é a empresa de pessoas específicas, o que acontece quando os profissionais saem da empresa, o treinamento de substitutos e os processos de segurança do sistema para que os ex-funcionários não tenham mais acesso. As respostas estão citadas abaixo.

Turn-over:

Sobre a perda de conhecimento, ocasionada pelo turnover na empresa, as respostas foram muito variáveis, indo de empresas com processos bem definidos para evitar perda de conhecimento e outras ainda em fase de estruturação.

Nosso turn-over é muito baixo $(<0,5 \%)$. A empresa tem um programa intensivo de trainees e de carreira. A empresa atrai facilmente novos talentos (E1).

A companhia está estruturando um programa de gestão do conhecimento associado a uma política de segurança da informação rigorosa. Com isso, um dos objetivos que esperamos atingir é exatamente a prevenção deste tipo de fuga de conhecimento, diminuindo o turn-over. (E2).

Para nossa organização seria catastrófica uma taxa de turnover alta. Temos uma taxa normal de $+/-0,8 \%$ de turnover para os mensalistas e de $+/-1,5 \%$ para os horistas, sendo que em relação apenas aos pedidos de demissão esta taxa cai a +/- 0,04 \%. O aumento de um turnover espontâneo nos cargos operacionais não seria problema, pois temos um sistema estruturado para capacitar de forma rápida pessoas sem conhecimentos específicos em fabricação de motores. Porém, no caso de pessoal especializado (foco na Engenharia de processo e Engenharia de Produto) não temos como repor eventuais saídas sem que venhamos a perder um pouco do conhecimento. O mercado em que estamos inseridos não fornece recursos com experiência no ramo automobilístico. Desta forma, levamos um tempo considerável para a formação de nossos 
engenheiros. A entrada de muitos substitutos poderia paralisar estes setores. (E3).

Sobre a dependência da empresa de funcionários que detenham conhecimentos específicos, foi possível observar grandes preocupações dos respondentes e grandes dependências:

Pela complexidade, o conhecimento é distribuído normalmente em várias pessoas, mas em alguns casos (10\%) está concentrado (E1).

Somos uma companhia de classe mundial que possui mais de 40 mil empregados próprios e 120 mil terceirizados, atuando em vários segmentos econômicos. A companhia está totalmente automatizada e informatizada, no entanto ainda existem alguns gaps que derivam dos conhecimentos particulares de alguns empregados que são expoentes em suas respectivas áreas de atividades. Caso estes empregados deixem a companhia, certamente alguns problemas surgirão. Principalmente se eles forem parar na concorrência e levarem consigo informações estratégicas sobre novos projetos e investimentos. (E2)

Em 2004 ficamos mais dependentes de certos especialistas, isto ocorreu pela rápida inversão nos processos de desenvolvimento de novos produtos (Engenharia de Produto). Foi transferida ao Brasil a responsabilidade de desenvolver por completo os motores para 0 Mercosul. Alguns engenheiros foram treinados no exterior e outros países para lidar com os novos processos e tecnologias (simulação de motores, transmissão automática, etc.). (....) não conseguimos ainda compartilhar de forma estruturada o know how aprendido com outros engenheiros da organização, criando assim um "back up de conhecimento". (E3)

A empresa é muito dependente de cada pessoa, principalmente nos segmentos de high end, onde o conhecimento do produto, do mercado e das pessoas é diferencial competitivo. $10 \%$ das pessoas da empresa são responsáveis pelos produtos de high end (alto valor) e correspondem a $40 \%$ do faturamento da empresa (E4).

Saída de funcionários "chave"

Sobre o impacto, na empresa, da saída de funcionários considerados "chave" e que detenham conhecimentos específicos, os respondentes mostraram grande preocupação:

Em minha opinião, devido à fuga de conhecimento derivada da saída dos empregados, os prejuízos financeiros são muito grandes e podem colocar até mesmo a sobrevivência das empresas em jogo. Daí a necessidade de haver uma fiscalização efetiva e sistemática de todo conhecimento produzido dentro das empresas. (E2)

A saída destes funcionários poderia colocar em risco o cumprimento do plano de lançamentos de novos produtos, o qual é vital para nosso cliente principal. Pelo fato destas pessoas estarem normalmente bem envolvidas nos processos estratégicos da organização, poderia ocorrer o vazamento de informações estratégicas de novos produtos. A concorrência teria muito interesse em contratar este pessoal, em função não só do conhecimento pessoal, mas também pelo conhecimento organizacional que estas pessoas possuem sobre modelo de gestão, métodos, processos. 
Porém, por se tratar de uma multinacional, teríamos a alternativa de trazer um especialista do exterior para momentaneamente cobrir a falta, mas seguramente não seria uma operação de fácil realização. (E3)

Imenso. O conhecimento se perde. Já conversamos sobre esta hipótese e neste caso o diretor da empresa está ciente do risco e se sujeita a perder competitividade se esta pessoa se for, mas não tem como aumentar o efetivo para a operação. (E4)

Sobre os procedimentos que a empresa desenvolveu para que o conhecimento não seja perdido para sempre e possa ser mantido dentro da organização, as respostas foram evasivas, em algumas das empresas. Em outros casos, as respostas foram bastante preocupantes:

Manutenção de baixo turn-over, retenção de talentos no preventivo e plano de carreira e formação contínua de equipes. A empresa valoriza o conhecimento e paga por isso com certo nível de redundância. (E1)

Os primeiros passos estão sendo dados. No entanto, ainda não há nada estruturado ou decidido de forma definitiva. (E2)

Classificamos esta situação como know how critical. Nestes casos, avaliamos, junto com a liderança de cada área, quais são os know how critical em função de algumas orientações, tais como: a) quando apenas 1 (um) profissional detém este conhecimento e ele é considerado "Core" para a organização, b) dificuldade em encontrar o know how disponível no mercado local, c) sinais de que o especialista pretende deixar a empresa, d) facilidade ou não de se criar um contexto para transferência de conhecimento para outra pessoa na organização, (...), etc. Após a identificação do know how critical, a liderança junto com o RH prepara um plano de desenvolvimento de uma outra pessoa na organização que possa ser preparada para substituir ou mesmo ajudar/potencializar o empregado. (E3)

Do ponto de vista de gestão do conhecimento, nenhum. O conhecimento não é foco da estratégia da empresa e não há motivação para partilhá-lo. (E4)

\section{Estratégia de preparação de substitutos}

Sobre a estratégia de treinamento de profissionais substitutos, no caso de perda do profissional titular, observa-se uma variedade grande, desde contratação de novos profissionais no exterior até a falta total de estratégia:

- Isso pode incluir treinamento no exterior. A empresa tem poder de atrair talentos prontos. (E1)

- Não se tem conhecimento (de estratégias) de forma oficial. (E2)

- A empresa tem um programa muito bem estruturado no caso de operadores de produção. No caso recente das novas admissões de especialistas para a área de engenharia, foi desenvolvido um programa para integração dos mesmos que levou em consideração cursos técnicos, metodológicos e 
comportamentais; outra prática constante é a realização de programas trainees. Neste programa, temos a possibilidade de trabalhar por 1 a 1,5 anos com os trainees, capacitando-os para o exercício de suas futuras funções. (E3)

- Sim, nos primeiros três meses a pessoa passa por todos os setores da empresa para familiarizar-se com os processos. (E4)

\section{Acesso de ex-funcionários}

Sobre o risco de acesso de ex-funcionários aos sistemas de informações da empresa e à base de conhecimento explícito, as empresas se mostraram bem estruturadas.

São imediatamente removidos da lista de usuários. É crescente o emprego de criptografia nas mensagens. (E1)

Basicamente são procedimentos já previamente definidos e consolidados que são executados pelas áreas de TI e Segurança Empresarial. Porém, por determinações internas não podemos revelar. (E2)

Quando estes saem da empresa, a área de Informática providencia seus respectivos descadastramentos do sistema. A informática possui sistemas de segurança que buscam gerenciar a entrada e saída de informações importantes. (E3)

Basicamente, é comunicada a toda a empresa a saída do funcionário, seu acesso é proibido e o acesso ao sistema é cancelado. (E4)

A pesquisa incluiu uma série de questões relativas aos riscos de vazamento de conhecimento provocado pela terceirização de serviços. Seguem as respostas.

\section{Profissionais e serviços terceirizados}

Sobre a proporção e tipos de profissionais terceirizados, as empresas demonstraram estratégias bastante diferentes, dependendo do setor em que atuam. Quando questionados se mantinham profissionais terceirizados, responderam:

Muito pouco. Menos que 20\%. Inclui obras civis e montagens industriais. No caso de P\&D existe sub-contratação do CESAR e GENIUS usando a lei da informática. A terceirização é feita na China e Polônia. (E1)

É política da companhia terceirizar todas as áreas que não são atividade fim. Porém, algumas áreas meio são estratégicas e não podem ser terceirizadas. (E2)

A maioria dos fabricantes de motores a combustão usina apenas as principais peças do motor bloco/cabeçote/virabrequim e biela, e terceira o resto. (...) Outra característica importante é que no desenvolvimento de produto terceirizamos a parte de desenhos/CAD. Em finanças, terceirizamos a parte de contas a pagar. $\mathrm{Em} \mathrm{RH}$, terceirizamos a 
freqüência/ registros/ e folha de pagamento. Na manufatura, terceirizamos o abastecimento de linha, almoxarifado e manutenção. (E3)

A empresa possui uma rede de distribuidores em vendas que responde por $20 \%$ do faturamento, o restante a empresa não terceiriza. (E4)

Sobre os riscos associados à terceirização, as respostas foram bem diversificadas, ressaltando-se o vazamento de conhecimento para os concorrentes, pois os fornecedores participam de várias redes.

Maior risco são os de qualidade e prazo de entrega. Isso é controlado por metodologia de PM-Project Management. . (E1)

São muitos. No entanto, em se tratando de Brasil, o maior deles é a responsabilidade solidária em passivos trabalhistas. (E2)

Os riscos são: a transferência de informação estratégica, pois estes fornecedores também fornecem para nossos concorrentes, dependência de um único fornecedor local (...), grande influência dos componentes adquiridos de nossos fornecedores na performance final de nosso produto junto ao cliente (erros de fornecedores podem destruir a imagem de nosso produto junto ao cliente). (E3)

Perder o controle da efetividade da atuação no mercado (E4)

Pelo resultado da pesquisa exploratória, observa-se que o vazamento de conhecimento acontece intensamente entre os funcionários e colaboradores das empresas, no contato com o mundo dos negócios e com as redes das quais participam. O vazamento está associado ao relacionamento entre fornecedores, distribuidores, clientes, concorrentes, parceiros, etc. Este vazamento pode ser intencional ou não. Entender este processo passa a ser um novo desafio para as empresas, que devem planejar que tipo de conhecimento deve ser compartilhado, visando o aumento da capacidade inovativa e da sua competitividade, conforme ressaltado por Bessant, Kaplinsky et al. (2003; 2003a).

\section{Comparação dos resultados com estudos realizados no Reino Unido}

Em estudo recente, realizado por Mohamed et al (2006) com 6 empresas inglesas, dos ramos de manufatura e projeto, pôde ser constatado que o vazamento de conhecimento acontece de forma intencional ou não, com impactos positivos e negativos (Quadro 1).

Os dois principais vazamentos intencionais e positivos observados na pesquisa inglesa foram: via contratação de trainees e através da participação de funcionários em cursos externos. O principal vazamento negativo, considerado não intencional, foi relativo à contratação de funcionários chave da empresa pelos concorrentes. Como exemplo de vazamento intencional negativo foi citado o caso de um consultor em TI, que tinha acesso total aos sistemas da empresa e que, portanto, tinha a oportunidade de copiar qualquer base de conhecimento da organização.

Apenas duas das 6 empresas pesquisadas na Inglaterra apresentaram planos para a substituição imediata de funcionários "chave", 
no caso de saída dos mesmos. Na maioria dos casos, o novo funcionário acaba tendo de reaprender todo o know how do novo serviço, começando normalmente do ponto zero. Este fato é particularmente grave quando o conhecimento do antigo funcionário não está incorporado em estruturas, procedimentos, normas, manuais, patentes, sistemas de informação, etc.

$\mathrm{Na}$ pesquisa realizada no Brasil, também se pôde observar vazamentos de conhecimentos, intencionais ou não, com impactos positivos e negativos. Nos contextos onde o fato ocorreu, foram percebidas questões referentes à comunicação entre profissionais, comunicação em treinamentos e atividades participativas, e aplicação de ferramentas de tecnologia e sistemas de informação, confirmando alguns dos cenários levantados na literatura e que motivaram a pesquisa.

De maneira geral, as empresas explicitaram que o conhecimento precisa ser valorizado e protegido, pois representa um dos fatores críticos para a competitividade das mesmas. As parcerias com universidades foram citadas como forma de produzir novos conhecimentos através do desenvolvimento de pesquisas. As contratações de novos talentos e as universidades corporativas foram citadas como forma de aquisição contínua de conhecimento pelas empresas e pelos funcionários. Estes são exemplos de vazamentos intencionais e positivos de conhecimento.

Como forma de minimizar o vazamento de conhecimento negativo, foi observada a preocupação das empresas em manter um turn-over baixo, evitando assim a perda de conhecimento para a concorrência. A perda de funcionários tidos como "chave" ainda continua sendo um dos desafios das empresas brasileiras pesquisadas, que nem sempre preparam substitutos para estes postos. Os consultores foram citados, em particular, como sendo um canal propício e tido como "perigoso" para o vazamento intencional de conhecimento com impactos negativos para a empresa, devendo, portanto ser monitorado constantemente. Estes pontos coincidem com aqueles levantados na pesquisa com empresas inglesas.

Algumas fragilidades observadas nas empresas brasileiras foram relativas à captura do conhecimento dos funcionários. Algumas empresas citaram que o registro do conhecimento estratégico é realizado através de portais corporativos, procedimentos e normas. Outras empresas ainda não dispõem de mecanismos para captura do conhecimento, mostrando não estarem ainda preparadas para a efetiva proteção do conhecimento. 0 mesmo aspecto foi observado na pesquisa inglesa, sinalizando ser este um desafio global.

\section{Considerações finais}

Este artigo teve como objetivo principal fazer um estudo exploratório sobre o comportamento de empresas brasileiras em relação à proteção do seu conhecimento, e analisar o conceito de vazamento de conhecimento e suas principais rotas. Nesta análise foi usada uma taxonomia apresentada na literatura para caracterizar este conceito. 
Foram apresentados os resultados de estudos de caso com empresas que atuam no Brasil e foi feita uma breve comparação com uma pesquisa realizada na Inglaterra.

Quando questionados sobre a definição do termo "vazamento de conhecimento" e sobre as suas conseqüências, os entrevistados se mostraram informados sobre esta questão e preocupados com os impactos deste vazamento para a empresa. Observou-se que o vazamento é ainda fortemente associado aos impactos negativos e não aos impactos positivos, conforme descrito na literatura. As principais rotas de vazamento positivo de conhecimento foram: contratação de talentos, treinamento, parcerias com universidades tradicionais, além dos benefícios das universidades corporativas. Os consultores foram citados como sendo uma possível rota de vazamento de conhecimento, com impacto negativo, devendo sua atividade ser monitorada. Além disto, foi mostrada grande preocupação com a perda de funcionários "chave" para a concorrência, que representa outra rota de vazamento de conhecimento com impacto negativo. Outras rotas citadas foram: roubo, desleixo ou indiferença do colaborador, falhas no sistema eletrônico, revistas e jornais da empresa, serviços terceirizados e até mesmo a espionagem industrial.

Pôde-se concluir que as empresas brasileiras pesquisadas já estão atentas para algumas rotas de vazamento de conhecimento e para os impactos positivos e negativos deste vazamento, mas muito ainda precisa ser feito para uma gerência eficaz deste processo, visando maximizar os efeitos positivos, minimizar os negativos e proteger o seu conhecimento estratégico.

Considera-se que a pesquisa seja relevante, pois ainda não são bem compreendidas as rotas através das quais o conhecimento vaza das empresas, seja através do fluxo de pessoas ou dos seus relacionamentos nas redes. Uma das reflexões que o artigo proporciona está relacionada ao fato de que, apesar das grandes vantagens que as redes com acesso aos conhecimentos tácitos podem propiciar, existem vários riscos associados à participação nas redes. Estes riscos devem ser analisados, de forma cuidadosa, pelos participantes. Um destes riscos é o vazamento de conhecimento estratégico, que pode trazer impactos negativos e positivos para a empresa.

\section{Referências}

ANNANSINGH, F. Exploring knowledge leakage risks exposure resulting from 3D modeling in organizations: a case study. Unpublished PhD research. Sheffield University, UK, 2005.

BESSANT, J., R. KAPLINSKY, et al. "Putting supply chain learning into practice." International Journal of Operations \& Production Management 23(2): 167-184, 2003.

BESSANT, J., R. KAPLINSKY, et al. "Developing capability through learning networks." International Journal of Technology Management \& Sustainable Development 2(1): 19-38, 2003a. 
CASTELLS, M. A sociedade em rede. São Paulo. Paz e Terra, 2000.

$\mathrm{CHOO}, \mathrm{C}$. W. Web Work: Information seeking and knowledge work on the world wide web. New York, Kluver Academic Publisher, 2000.

DYER, Jeffrey H. Specialized Supplier Networks As a Source of Competitive Advantage: Evidence from the Auto Industry in: Strategic Management Journal, Vol. 17, 271-291, 1996.

DYER, J.; NOBEOKA, K. Creating and managing a high-performance knowledge-sharing network: the Toyota case in: Strategic Management Journal, vol.21 March, 2000.

GIL, A. C. Como elaborar projetos de pesquisa. 4. ed. São Paulo: Atlas, 2002.

GULATI, R.; NOHRIA, N.; ZAHEER, A. Strategic Networks in: Strategic Management Journal, vol.21 March, 2000.

JAMIL, G. L. Gestão de informação e do conhecimento em empresas brasileiras: estudo de múltiplos casos. Belo Horizonte: C/arte, 2006.

KALAKOTA, R.; ROBINSON, M. E-Business: Estratégias para alcançar o sucesso no mundo digital - 2a. Edição. Porto Alegre, Bookman, 2002.

KOTLER, P.; ARMSTRONG, G. Princípios de marketing, 9a. Edição. São Paulo: Prentice Hall, 2003.

KALE, Prashant; SINGH, Harbir; PERLMUTTER, Howard. Learning and protection of proprietary assets in strategic alliances: building relational capital. Strategic Management Journal, vol.21, March, 2000.

PRAHALAD, C. K.; HAMEL, G. The core competence of the corporation. Harvard Business Review, v. 68, n. 3, p. 79-91, May/June, 1990.

TEIXEIRA, F. L. C. (Org.). Gestão de Redes de Cooperação Interempresarial: em busca de novos espaços para o aprendizado e a inovação. 1. ed. Salvador - Bahia: Casa da Qualidade, 2005. v. 1. 151 p.

KAPLINSKY, Raphael; GRANTHAM, Andrew; CHAN, Paul; COLES, Rhoda; WALSH, Kathryn; MYNORS; Diane and MOHAMED, Souad. Towards a Taxonomy of Knowledge Leakage: Literature and Framework, in Knowledge and Learning Track, BAM Conference, September, Belfast, 2006.

LUCAS Jr., H. C. Tecnologia da informação: tomada de decisão estratégica para administradores. Rio de Janeiro: LTC, 2006.

MOHAMED, S.; GRANTHAM, A.; WALSH, K.; CHAN, P. Understanding one aspect of the knowledge leakage concept: people in: European and Mediterranean Conference on Information Systems (EMCIS), July, Costa Blanca, Alicante, Spain, 2006.

REAGANS, R.; Mc EVILY, B. Network structure and knowledge transfer: the effects of cohesion and range. Administrative Science Quarterly, v.48, p. 240-267, 2003. 
RUDIO, F. V. Introdução ao projeto de pesquisa científica. $16^{\mathrm{a}}$ ed. Petrópolis: Vozes, 1986.

VASCONCELOS, M. C. R. L MILAGRES, R. NASCIMENTO, E. Estratégia de Relacionamento entre os Membros da Cadeia Produtiva no Brasil: reflexões sobre o tema.in: G\&P - Gestão \& Produção, v. 12, n.3, p.393404, set-dez 2005.

YIN, Robert K. Estudo de caso: planejamento e métodos. Porto Alegre: Bookman, 2001.

YOSHINO, M.; RANGAN, U. Alianças estratégicas: uma abordagem empresarial à globalização. São Paulo: Makron Books, 1996. 